East African Medical Journal Vol. 86 May 2009

SOCIO-DEMOGRAPHIC AND CLINICAL ASPECTS OF RHEUMATOID ARTHRITIS

B. O. Owino, MBChB, MMed, Consultant Physician, Kenyatta National Hospital, P.O. Box 20723-00202, Nairobi, Kenya, G. O. Oyoo, FACR, Senior lecturer and C. F. Otieno, MBChB, MMed, Senior Lecturer, Department of Clinical Medicine and Therapeutics, College of Health Sciences, University of Nairobi, P.O. Box 19676 - 00202, Nairobi, Kenya

Request for reprints to: Dr. B.O. Owino, P. O. Box 20723- 00202, Nairobi, Kenya

\title{
SOCIO-DEMOGRAPHIC AND CLINICAL ASPECTS OF RHEUMATOID ARTHRITIS
}

\author{
B. O. OWINO, G. O. OYOO and C. F. OTIENO
}

\begin{abstract}
Objective: To determine the socio-demographic profiles and some clinical aspects of patients with rheumatoid arthritis (RA).

Design: Prospective, cross-sectional study.

Setting: Ambulatory out-patient clinics of Kenyatta National Hospital (KNH), a public national and referral hospital.

Subjects: Out of 180 patients interviewed and examined, 60 met American College of Rheumatology (ACR) diagnostic criteria of RA.

Results: Of the 60 patients recruited $52(87 \%)$ were females with male: female ratio of 1: 6.5. The mean age of patients was $41.38( \pm 16.8)$ years. There were two peaks of age of occurrence, $20-29$ and $40-49$ years. In $75 \%$ of the study patients, one or more of metacarpophalangeal joints of the hand were involved in the disease. Other frequently involved sites were - wrists, elbows, knees, ankles and glenohumeral joints of shoulders in a symmetrical manner. Serum rheumatoid factor was positive in $78.9 \%$ while rheumatoid nodules were present in $13.3 \%$ of the study patients. A large majority of patients $(88 \%$ ) had active disease with $18 \%$ having mild disease, $38 \%$ moderate activity and $32 \%$ having severe disease. Only $12 \%$ of patients had disease in remission. Forty six point seven per cent $(46.7 \%)$ of the study patients were on at least one Disease Modifying anti Rheumatic Drugs (DMARD) from a selection of methotrexate, sulphasalazine, hydroxychloroquine and leflunamide. The most frequent drug combination was methotrexate plus prednisolone at $30 \%$ of the study population; while $66.7 \%$ were on oral prednisolone with $25 \%$ of the study patients taking only Non-Steroidal anti Inflammatory Drugs (NSAIDS).

Conclusion: A large majority of ambulatory patients with RA had active disease. Most of' them were sub-optimally treated, especially the use of DMARDS. About two thirds were on oral steroids. Sub-optimal therapy in relatively young patients, peak 20-29 and 40-49 years is likely to impact negatively on their disease control and quality of life.
\end{abstract}

\section{INTRODUCTION}

Rheumatoid arthritis is a chronic systemic autoimmune inflammatory disorder characterised by deforming symmetrical polyarthritis of varying extent and severity, associated with synovitis of joint and tendon sheaths, articular cartilage loss, erosion of juxta-articularbone and, in most patients, the presence of IgM rheumatoid factor in the blood. In some patients systemic and extra-articular features may be observed during the course of the disease and, rarely, prior to onset of joint disease. These include anaemia, splenomegally, weight loss, vasculitis, serositis, mononeuritis multiplex, interstitial inflammation in the lungs and exocrine salivary and lacrimal glands, as well as nodules in subcutaneous, pulmonary and scleral tissue (1). Rheumatoid arthritis is a disease with regional variation in prevalence, severity, age at onset and female to male ratio of patients affected (1-17). Except for west Africa where the incidence of rheumatoid arthritis has remained low and the disease is mild (1), studies in the rest of Africa have recorded increasing prevalence and, in some cases, increasing severity of the disease (3-14). In a prospective study at KNH by Bagg et al (13) in 1969, they managed to review 76 cases of RA over a period of eighteen months. In terms of age, sex, pattern of joint involvement, and nodularity, these patients more closely resembled their European counterparts than they did those described in West Africa by Greenwood 
(7). The disease and its management at $\mathrm{KNH}$ has not been reviewed since, despite a clinical impression that we are seeing increasing numbers of, mostly, severe disease in the back ground of what appears to be sub optimal treatment.

\section{MATERIALS AND METHODS}

Study population: The study was conducted on patients attending the medical outpatient clinic at Kenyatta National Hospital which is thenational referral health institution located in Nairobi, the capital city of the republic of Kenya.

Patient recruitment: Memos to clinicians soliciting for patients were posted in various departments at the KNH. Patients referred for the study with established or suspected diagnosis of RA (defined according to the ACR 1987 revised criteria) were screened consecutively. All patients of both sexes aged thirteen years and above, with own or legal guardian's signed consent, who also met the ACR criteria for classification of RA were recruited. All recruited patients had their ages, sexes, employment status, level of education and medical treatment history recorded by the investigator on an already prepared questionnaire.

Each of these patients was then physically examined for pattern of joint involvement with, RA, presence of rheumatoid nodules and any other extra-articular manifestation of RA, presence of any co-morbid conditions, followed by an assessment of severity of disease using DAS-28. This information was also recorded on a prepared data sheet by the investigator.

Laboratory methods: A celdyn 3200 series coulter machine was used for FBC, and Wintrop method for ESR determinations. Normal ESR by this method are $0-20 \mathrm{~mm} / \mathrm{hr}$ and $0-9 \mathrm{~mm} / \mathrm{hr}$ for females and males respectively. IgM rheumatoid factor was determined using RA latex test, which is a standard latex agglutination test with both negative and positive controls. With this test the presence of agglutination indicates a level of RF in the sample equal to or $>81 . \mathrm{u} / \mathrm{ml}$, while a negative result indicates a level of $\mathrm{RF}$ in the sample of $<81 . \mathrm{u} / \mathrm{ml}$. Blood for RF test was only drawn from those patients without a previous positive RF test result.
Ethical considerations: The study was done after receiving consent from the $\mathrm{KNH}$ ethical and research committee, and was only carried out on adult patients who had given informed consent or those below the age of 18 years only with informed consent of their parents or legally recognised guardians.

Data analysis: Data was analysed using SPSS computer software package. Continous variables were categorised in ranges and summarised into means, medians, modes, and standard deviations. Quantitative data was presented in frequency distribution tables and bar diagrams. Relationships between age and severity of disease were analysed by Pearson correlation coefficient, while that between level of education or employment status and severity of disease was analysed by Mann-Whitney U and Wilcoxon tests. Severity of disease and type of drug treatment were analysed using one way ANOVA and Kruskal- Wallis one way ANOVA. A significant association was deemed present at a P-value of $<0.05$.

\section{RESULTS}

A total of 180 patients, aged thirteen years and above, were screened for rheumatoid arthritis from $6^{\text {th }}$ September 2005 to $4^{\text {th }}$ April 2006. Sixty of them satisfied the inclusion criteria and were recruited for the study. Of the 60 patients, eight were male and 52 female (M: F = I: 6.5). Characteristics of the study population is depicted in Table 1. Mean age of patients was $41.38 \pm 16.78$ (range was 14 to 85 years). There were two peak age brackets, 20 - 29 and 40 - 49 years. The age distribution of the recruited patients is as shown in Figure 1.

\section{Figure 1}

The age distribution of the patients with rheumatoid arthritis

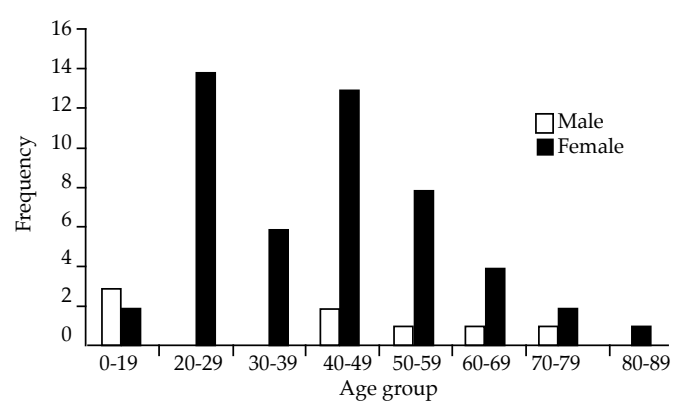


Table 1

Characteristics of the study population $(n=60)$

\begin{tabular}{lc}
\hline Characteristic & Population \\
\hline Male: Female ratio & $1: 6.5$ \\
Age: 14-85 years & $41.38 \pm 16.78$ \\
Level of education (\%) & \\
$\quad$ None & 11.7 \\
Primary & 40.0 \\
Secondary & 28.3 \\
College & 13.3 \\
University & 5.0 \\
Joint involvement-MCPJ and PIPJ $(\%)$ & 75 \\
Rheumatoid factor positive (\%) & 78.9 \\
Rheumatoid nodules present $(\%)$ & 13.3 \\
DAS-28 (\%) & \\
Remission ( $\leq$ 2.6) & 12 \\
Mild (> 2.6-3.2) & 18 \\
Moderate (> 3.2-5.1) & 38 \\
High (> 5.1) & 32 \\
Drug treatment (\%) & \\
At least one DMARD & 46.7 \\
Prednisone alone & 21.7 \\
NSAID alone & 25.0 \\
No recall / No drug & 6.67 \\
Co-morbid conditions (number) & \\
Hypertension & 11 \\
Peptic ulcer disease & 5 \\
Diabetes mellitus & 2 \\
\hline
\end{tabular}

MCPJ=Metacarpo-Phalangeal Joint, PIPJ=Proximal Inter-Phalangeal Joint.

The percentage of the patients with level of education of primary school and below was $51.7 \%$, while primary together with secondary level education accounted for the highest figure of $68.3 \%$. A large majority of the patients $(70.2 \%)$ were unemployed whilethe remaining $29.8 \%$ were in paid employment (Figure 2 ).

Figure 2

Pattern of employment status among the study patients

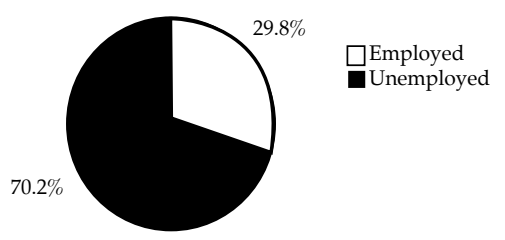

In $75 \%$ of the study patients, one or more of the metacarpophalangeal and proximal interphalangeal joints of the hand were involved by RA. Other frequently involved sites included wrists, elbows, knees, ankles and gleno-humeral joints of the shoulders. Four patients, three females and one male, had severe deforming and disabling joint disease. Serum rheumatoid factor was positive in $78.9 \%$, while rheumatoid nodules were present in $13.3 \%$. Patients with rheumatoid nodules had moderate to severe disease.

A large majority of patients (88\%) had active disease, with mild disease accounting for $18 \%$, moderate disease $38 \%$ and severe disease $32 \%$. The remaining $12 \%$ of the patents had inactive disease [remission]. The overall mean value for disease activity score was $4.39 \pm 1.67$, with females having a significantly higher mean score of $4.58 \pm 1.61$ compared to that of their male counterparts which was $3.16 \pm$ 1.66 $(\mathrm{P}=0.019)$. The disease severity (DAS-28) pattern is illustrated in Figure 3. There was no correlation between disease activity score and age $(\mathrm{p}=0.69)$, level of education $(\mathrm{P}=0.92)$ or employment status $(\mathrm{P}=0.52)$ among the study patients.

Figure 3

Severity of disease (DAS - 28) pattern in the study patients

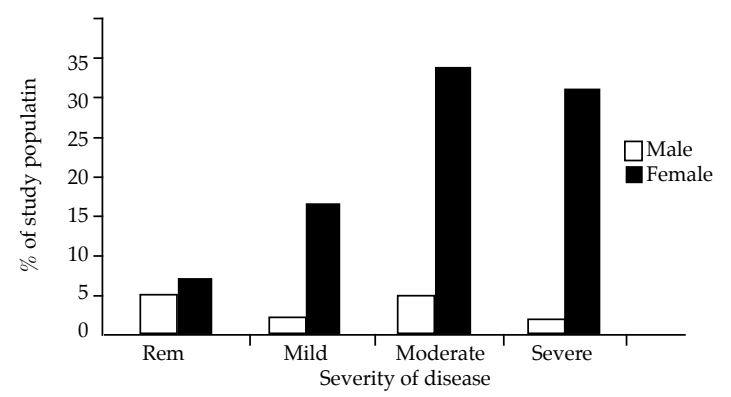

DAS-28 was categorised as: $\leq 2.6$ (remission),$>2.6-3.2$ (mild), > 3.2-5.1 (moderate), > 5.1 (high).

Twenty eight $(46.7 \%)$ of the sixty study patients were on treatment with at least one disease modifying anti-rheumatic drug (DMARD) from a selection of methotrexate (MTX), sulfasalazine (SSZ), hydroxychloroquin (HCQ) and the biologic leflunomide(Arava). The most commonly prescribed DMARD was MTX in $26(43.3 \%)$ of the sixty study patients, followed by SSZ in nine patients $(15 \%)$ and HCQ in three patients (5\%). There were two patients on the triple DMARD combination therapy of MTX, SSZ and HCQ. The most frequent drug combination was MTX plus prednisonein $18(30 \%)$. Forty $(66.7 \%)$ of the sixty study patients were on oral prednisone with only five (12.5\%) taking oral calcium supplements.

Fifteen patients $(25 \%)$ took only non-steroidal anti-inflammatory drugs while eighteen $(30 \%)$ of the 
study patients took drugs only intermittently. Three of the sixty study patients could not recall the drugs they had used, while one patient had not been on any drug therapy despite severe disease (DAS-28 of 6.12). Of the patients on prednisone $25(62.5 \%)$ were taking high dose (10 mg or more) while $15(37.5 \%)$ were on low dose $(<10 \mathrm{mg})$. The distribution of drug treatment in the study population is summarised in Table 2. Four of the study patients with severe disease not responding to the synthetic DMARDs, were on leflunomide.

Table 2

Distribution of drug treatment among the study patients

\begin{tabular}{lcc}
\hline Drug & Frequency & $\begin{array}{c}\% \text { of } \\
\text { study } \\
\text { patients }\end{array}$ \\
\hline MTX + Prednisone & 18 & 30.00 \\
MTX + SSZ + Prednisone & 5 & 8.00 \\
MTX + HCQ + Prednisone & 1 & 1.67 \\
SSZ + Prednisone & 2 & 3.33 \\
MTX + SSZ + HCQ & & \\
+ Prednisone & 2 & 3.33 \\
NSAIDs alone & 15 & 25.00 \\
Prednisone alone & 13 & 21.70 \\
No drug & 1 & 1.67 \\
No recall & 3 & 5.00 \\
\hline Total & 60 & 100 \\
\hline
\end{tabular}

The twenty eight study patients who were on DMARD therapy were also found to have a lower mean disease activity [DAS-28] score of $4.23 \pm 1.61$ compared to the mean DAS-28 score of $4.56 \pm 1.80$ in the other 28 study patients who were not on DMARDs, but the difference was not significant though, $\mathrm{p}=0.44$ (Table 3 ). On the other hand there was a significantly lower mean DAS-28 score (4.06 $\pm 1.60)$ in the 38 study patients on regular drug treatment compared to that in the 18 study patients on intermittent drug treatment $(5.08 \pm 1.74), \mathrm{p}=0.028$ (Table 4).

The mean disease activity score for those study patients who were on NSAIDs alone (4.98) washigher than that for those on DMARD therapy (4.23), but the difference was not significant $(p=0.108)$.

One patient, a female, out of the sixty study patients had undergone corrective surgery for complications of rheumatoid arthritis. She had bilateral hip joint replacement and corrective surgery for a badly damaged left knee joint. Thirteen of the study patients had been on physiotherapy; three on occupational therapy and one had psychiatric management.

Twenty out of the sixty study patients had at least one co-morbid condition as presented in Table 5. The most common co-morbid condition was arterial hypertension, accounting for 11 out the 20, followed by peptic ulcer disease (five patients) and diabetes mellitus (two patients).

Table 3

The relationship between DMARD therapy and mean DAS-28 scores among the study patients

\begin{tabular}{llllll}
\hline $\begin{array}{l}\text { DMARD } \\
\text { treatment }\end{array}$ & No. & $\begin{array}{l}\text { Mean DAS- } \\
28 \text { Score }\end{array}$ & $\begin{array}{l}\text { Median DAS- } \\
28 \text { Score }\end{array}$ & $\begin{array}{l}\text { Std. } \\
\text { Deviation }\end{array}$ & $\begin{array}{l}\text { Asymp. } \\
\text { (2-Tailed) } \\
\text {-value }\end{array}$ \\
\hline Yes & 28 & 4.2271 & 1.60516 & 3.4700 & 0.441 \\
No & 28 & 4.5579 & 1.80454 & 4.3900 & \\
\hline Total & 56 & 4.3925 & 1.70037 & 3.9350 & \\
\hline
\end{tabular}

Table 4

The relationship between mean DAS-28 scores and consistency on drug treatment among the study patients

\begin{tabular}{llllll}
\hline & & Mean & Median & Std. & $\begin{array}{l}\text { Asymp. } \\
\text { (2-Tailed) } \\
\text { Consistency }\end{array}$ \\
of treatment & No. & DAS- & DAS- & Deviation & p-value \\
\hline Regular & 38 & 28 score & 28 score & & 0.028 \\
Intermittent & 18 & 4.0647 & 1.60213 & 3.4350 & 5.1200 \\
\hline Total & 56 & 5.0844 & 1.73794 & 3.9350 & \\
\hline
\end{tabular}


Table 5

Co-morbid conditions among the study patients

\begin{tabular}{lcc}
\hline Co-morbid condition & Frequency & $(\%)$ \\
\hline HTN & 6 & 10.0 \\
PUD & 3 & 5.0 \\
Eye cataract & 1 & 1.7 \\
PTB & 1 & 1.7 \\
Skin lesions & 1 & 1.7 \\
HHD & 1 & 1.7 \\
Fibroids & 1 & 1.7 \\
Asthma & 1 & 1.7 \\
HTN \& PUD & 2 & 3.3 \\
HTN \& DM & 2 & 3.3 \\
Anaemia & 1 & 1.7 \\
\hline Total & 20 & 33.4 \\
\hline
\end{tabular}

HTN = Hypertension, PUD= Peptic Ulcer Disease; PTB=Pulmonary Tuberculosis;

HHD = Hypertensive Heart Disease; $\mathrm{DM}=$ Diabetes Mellitus

\section{DISCUSSION}

The sixty patients with rheumatoid arthritis seen in this study in a period covering only seven months shows that the number of cases seen at $\mathrm{KNH}$ with this diagnosis have risen markedly over the years. This is so because in the last documented study on RA at KNH by Bagg et at and published in 1979 (13), they managed to see 76 patients with RA over a much longer period of eighteen months. This rise in the number of cases may be a reflection of increasing health awareness among Kenyans, a better referral system, the presence of a rheumatologist at $\mathrm{KNH}$, or it could be as a result of increasing urbanisation in Kenya, as studies in South Africa and in the USA have shown increased prevalence of RAin urban compared to rural populations (1). It could also be as a result of the difference in the population of Nairobi between then and now. On the other hand there could be a true rise in the prevalence of RA in Nairobi, but that can only be ascertained by conducting a well-designed community based study.

The mean age of patients of 41.3 recorded in this study is lower than the 43 years by Bagg et at (13), and the 44.5 years by Oyoo (23), although the double peak age groups of 20-29 and 40-49 years recorded in this study did not feature in their studies. The age characteristics found in the three studies are however younger compared to those recorded in a study in the United Kingdom by Wiles (18), who found a peak age of 45-74 years for females and 65- 74 years for males. This difference could probably be a reflection of the generally younger Kenyan population compared to that of the United Kingdom. Similarly younger age groups in black patients (36.6 years) compared to caucacian patients (44.2 years) with RA have however been recorded in South Africa by Mody (19), and by Adebajo and Reid in a study in Nigeria (20), and could therefore probably be due to a real racial difference.

The male to female ratio of 1:6.5 recorded in this study is close to the $1: 5$ by Oyoo (23), but markedly higher than the 1:2.8 by Bagg et al (13), the 1:1.5 in Nigeria by Adebajo and Reid (20), the 1:1.7 in Uganda by Kanyerezi (11), the $1: 2.3$ in Zimbabwe by Lutalo (21) and the 1:3.7 found in Durban, South Africa by Mody and Meyers (22), all of which are comparable with the 1: 3 found in most caucacian studies (2). The female preponderance widely reported in RA is thus accompanied by wide regional variation and indeed, in a study in Nigeria, no significant difference between the number of males and females with RA was recorded (24). A community based study is however necessary in order to come up with a more reliable figure for the local population.

Slightly more than half $(51.7 \%)$ of the study patients had a level of education of primary school and below, while the majority $(70.2 \%)$ were not in paid employment. This could probably reflect an institutional bias, most probably linked to the fact that $\mathrm{KNH}$ is a public institution likely to be attended by patients of low socio-economic status, or it could be a reflection of the level of unemployment and education among the general Kenyan population. It is also possible that RA is commoner in the lower social classes of our society, but this needs to be investigated in a community-based study. The association of RA with low level of education and unemployment as shown in this study would imply that these patients are unlikely to afford unsubsidised health care.

In $75 \%$ of the study patients, one or more of the metacarpophalangeal and proximal interphalangeal joints of the hand were involved by RA. Other frequently involved sites include wrists, elbows, knees, ankles and gleno-humeral joints of the shoulders. Serum rheumatoid factor was positive in $78.9 \%$ of the study patients. The pattern of joint involvement with RA and the prevalence of rheumatoid factor positivity recorded in this study are similar to those recorded in earlier studies in Kenya by Bagg et at (13), Houba et al (25) and to that found in the Caucasians (1).

The presence of rheumatoid nodules was however recorded in $13.3 \%$ of patients in this study compared to $31.6 \%$ by Bagg et al (13), $25 \%$ in Cape Town, South Africa by Mody and Meyers (22),7.9\% and $12 \%$ in two Ugandan studies by Kanyerezi et al (10) and Lutalo (21), and in only $1.4 \%$ in Nigeria by 
Green Wood (7). The presence of rheumatoid nodules, normally a marker of severe disease, did not appear to predict accurately for severe disease in this study.

Apart from rheumatoid nodules there were however no other extra-articular manifestations of rheumatoid arthritis recorded in this study. The other African studies where severe extra-articular manifestations of RA has been noted to be a rare feature include those by Greenwood in Nigeria (7), Anderson in South Africa (26) and Bagg et al (13).

Exceptions have however been reported in black Africans in Uganda by Lutalo (21), Moolenburgh et al (27) in Lesotho, and Mody and Meyers (22). In these studies a wide spectrum of extra-articular manifestations with involvement of the eye, lungs, heart, central nervous system, leg ulcers, hepatosplenomegally and lymphadenopathy were reported.

A large majority of patients (88\%) had active disease, with mild disease accounting for $18 \%$, moderate disease $38 \%$ and severe disease $32 \%$. Only $12 \%$ of the study patients were in disease remission. Bagg et al (13) used a radiological criteria (X-ray changes graded according to criteria of Kellgren) to categorise disease severity as grades $0-1,2,3$, and 4 in an ascending order of disease severity. Majority of their patients fell in grade $2(38 \%)$ and $3(36 \%)$, with $19 \%$ ingrade $0-1$ and only $7 \%$ in grade 4 . Their findings, though not amenable to direct comparison with this study due to difference in criteria used, would seem to suggest that the disease in those patients was less severe than that recorded in this study. Yet, even then, their findings as to disease severity were comparable to those found in an English study by Thould et al, (28) except for grade 4 disease, which accounted for $15 \%$ in the English study.

Other studies in black populations have found markedly mild disease compared to that in Caucasians, for example in a study in Nigeria Greenwood found 69\% in Kellgren grade 0-1 (21\%) in grade $2(8 \%)$ in grade 3 and only $2 \%$ in grade 4 $(7,13)$. Adebajo and Reid (20) did a comparative study between patients presenting with RA at a rheumatology unit in Nigeria and patients presenting to a British rheumatology unit. Apart from the west African patients being younger at disease onset with less frequent family history, fewer extraarticular features, fewer erosions and less commonly rheumatoid factor positive, the over-all mildness of their disease was striking. In another comparative study between pure black Bantu Zimbabwean and British white patients with RA, Chikanza et al (16), found that the Zimbabwean patients had a disease that was clinically and radiologically less severe with fewer extra-articular features compared to British white patients. It would therefore appear that, even among the black Africans, there is a wide regional variation in the severity of rheumatoid arthritis.
The patients' level of education and employment status showed no significant associations with disease severity, even though social deprivation is now recognised to have an important negative impact on morbidity and mortality in patients with RA independent of compliance with treatmentand disease duration (29). The lack of association recorded in this study could be due to small study sample, or presence of confounders like not receiving proper drug treatment, or both. There was no significant association between severity of disease and age among the study patients. It has been suggested that advanced age at onset of RA is associated with severe disease, but not in an independentmanner since aggressive diseaseislargely restricted to those elderly patients with high titers of rheumatoid factor (30). Thelack of association recorded in this study is therefore not unique. Similarly the lack of significant association between duration of illness and severity of disease was not an unexpected finding. It would however require well-designed longitudinal studies to investigate these associations.

Forty six per cent of the study patients were on treatment with at least one DMARD, the most commonly prescribed being MTX in $43 \%$ of the total study population. SSZ and HCQ were used by $15 \%$ and $5 \%$ of the study population respectively. There were only two patients on the triple DMARD combination of MTX, SSZ and HCQ in a study population with $70 \%$ moderate to high disease activity. However these were mostly recent referrals who had not been under the care of a rheumatologist for any reasonable period of time.

The scenario is quite different in the developed world where, with adequate drug therapy under the care of rheumatologists, they have been able to achieve disease remission in up-to $95 \%$ of their patients (31) compared to the $12 \%$ remission recorded in this study. The possible contributing factors to the low remission rate recorded in this study include poor compliance with medication, financial constraints and poor management due to scarcity of adequately trained medical personnel.

Sixty six point seven per cent of the study patients were on oral prednisone with $62 \%$ of them taking high dose (10mg or more of prednisone/ day), while only $12 \%$ of all those on prednisone took calcium supplements. This is in contrast to the current established practice of using low dose prednisone $(<10 \mathrm{mg} / \mathrm{d})$, in combination with calcium supplements, as a bridge to effective DMARD therapy to guard against the common side effects of steroids such as thinning of skin, hypertension, impaired glucose tolerance, dyslipidaemia and osteoporosis. Low dose prednisone has been shown to be as effective as high dose prednisone, but with an added advantage of less drug side effects (32). Similarly 25 of the study patients were on NSAIDs alone, despite the fact that NSAIDs alone have no place in the current management of 
rheumatoid arthritis as they have not been shown to slow down the progression of disease (32).

One patient, a female, out of the sixty study patients $(1.67 \%)$ had undergone corrective surgery for complications of rheumatoid arthritis. She had bilateral hip joint replacement and corrective surgery for a badly damaged left knee joint. Thirteen (21.67\%) of the study patients had been on physiotherapy; three $(5 \%)$ on occupational therapy and one $(1.67 \%)$ had psychiatric management. The percentage of patients needing surgery seems rather low in the background of a prevalence of active disease of $88 \%$. Probably the very disabled did not seek treatment at $\mathrm{KNH}$, or most of them were seen only by orthopaedic surgeons. The low percentage of patients receiving psychiatric management probably reflects adoption of other effective mechanisms such as optimism, comforting cognition, and social / family support to cope with the pain, disability and dependence attendant on RA.

A total of twenty out of the sixty study patients (33.4\%) had various co-morbid conditions (Table 8). The most common co-morbid condition was arterial hypertension accounting for 11 out of the 20 , followed by peptic ulcer disease (five patients) and diabetes mellitus (two patients). Some of these co-morbid conditions probably arose as side effects of prednisone and NSAID therapy but it is not possible to establish causation from this study.

The number of patients seen with rheumatoid arthritis continues to rise with time, affecting mostly young unemployed women with low level of education. This is an alarming scenario since such patients are unlikely to understand their disease and seek competent medical attention during the crucial first two months window of opportunity. Furthermore, because the majority of these patients are unemployed, they are unlikely to afford proper medical care. The young age at onset of RA with attendant physical disability is likely to further render these patients unemployable and therefore perpetual dependants in a socio-economic background of widespread poverty. Mechanisms need to be put in place to provide essential drugs free of charge, or at heavily subsidised prices for these patients.

The need to carry out well designed population based studies in order to get a true appraisal of the situation can not therefore be overemphasized.

It is only by knowing the true burden of this painful, deforming and disabling disease that we can be able to launch a rational and effective national healthcare approach to combat it. The task at hand is daunting, yet it must be tackled urgently.

\section{ACKNOWLEDGEMENTS}

To the KNH director's office and the Ethical Review Committee for approving the study. The KNH-MOPC nursing staff for assisting the booking and recruitment of patients and to the patients for accepting to participate in the study.

\section{REFERENCES}

1. Warrell, D. A., Cox, T. M., Firth, J.D., et al. Oxford Textbook of Medicine. Fourth Edition. New York. Oxford University Press Inc. 2003.

2. Kavita G., John J.N., Sarjoo M.B., et al. E-Med update on RA. 2004; 1-20.

3. McGill P. RA in sub-saharan Africa. Ann. Rheum. Dis. 1991; 50: 965-966.

4. Gefland, M. The sick African. A clinical study. Cape Town. Juta. 3rd ed 1957; 8-9.

5. Goodall, J. W. D. Joint swellings in Africans. Cent. Afr. J. Med. 1956; 2: 220-223.

6. Shaper, A. G. and Shaper. L. Analysis of medical admissions to Mulago hospital. East Afr. Med. J. 1957; 25: 647-678.

7. Greenwood, B. M. Polyarthritis in Western Nigeria. 1. Rheumatoid arthritis. Annals Rheum. Dis. 1969; 28: 488-496.

8. Harries, J. R. Rheumatoid nodules in an African. East Afr. Med. J. 1962; 39: 69-70.

9. Hall, L. Polyarthritis in Nairobi Africans. East Afr. Med. J. 1963; 4: 354-358.

10. Kanyerezi, B. R., Baddely, H. and Kisumba, D. Rheumatoid arthritis in Ugandan Africans. Ann. Rheum. Dis. 1970; 29: 617-621.

11. Kanyerezi, B. R. Some aspects of rheumatoid disease in Uganda. East Afr. Med. J. 1980; 57: 39-43.

12. Adebajo, O. A. and Reid, D.M. Rheumatoid arthritis in a West African and British teaching hospital in 1987. Br. J. Rheumatol. 1988; 27: (Suppl. 1): 14.

13. Bagg, L. R., Hansen, D.P., Lewis, C., et al. RA in Kenya. I. Clinical observations. Ann. Rheum. Dis. 1979; 38: 23-25.

14. Beighton, P., Solomon L. and Valkenburg, H. A. Rheumatoid arthritis in a rural South African Negro population. Ann. Rheum. Dis. 1957; 34: 136-141.

15. Thould,A.K. andSimon, G.Assessment of radiological changes in the hands and feet in rheumatoid arthritis. Ann. Rheum. Dis. 1966; 25: 220-228.

16. Chikanza, I. C., Stein, M., Lutalo, S., et al. The clinical, serologic, and radiological features of RA in ethnic black Zimbabwean and British Caucasian patients. J. Rheumatol. 1994; 21: 2011-2015.

17. McGill. P. E. and Oyoo, G.O. Rheumatic disorders in sub-saharan Africa. East Afr. Med. J. 2002; 79; 4: 214-216.

18. Wiles, N. Estimating the incidence of RA. Arth.rheum. 1999; 42: 1338-1346.

19. Mody, G.M. Rheumatoid arthritis in the western Capea clinical study. MD Thesis. University of Capetown. 1987.

20. Adebajo, A. O. and Reid, D. M. The pattern of rheumatoid arthritis in west Africa and comparison with a cohort of British patients. Quaterly J. Med.1991; 80: 633-640.

21. Lutalo, S.K.Chronicinflammatory rheumatic diseases in black Zimbabweans. Ann. Rheum. Dis. 1985; 44: 121-125. 
22. Mody, G. M., Meyers O. L. Rheumatoid arthritis in blacks in South Africa. Ann. Rheum. Dis. 1989; 48: 69-72.

23. Oyoo, G. O. Rheumatoid arthritis in Nairobi: demographic observations. Health Line. 2005; 9: 3-5.

24. Greenwood, B. M. and Herrick, E. M. Low incidence of rheumatoid factor and autoantibodies in Nigerian patients with rheumatoid arthritis. Brit. Med. J. 1970; 1: $71-73$

25. Houba, V., Bagg, L.R., Hansen, D.P., et al. RA in Kenya II, Serological observations. Ann. Rheum. Dis. 1979; 38: 26-30.

26. Anderson, I. F. Rheumatoid arthritis in the Bantu. South Afr. Med. J. 1970; 44: 1227-1229.

27. Moolenburgh, J. D., Mbore, S., Valkenburgh, H. A. et al. Rheumatoid arthritis in Lesotho. Ann. Rheum. Dis. 1984; 43: 40-43.
28. Thould, A.K. andSimon, G. Assessment of radiological changes in the hands and feet in rheumatoid arthritis. Ann. Rheum. Dis. 1966; 25: 220-228.

29. McEntegart, A. M., Morrison, E., Capell, H. A., et al. Effects of social deprivation on disease severity and outcome in patients with RA. Ann. Rheum. Dis. 1997; 56: 410-413.

30. Kasper, D.L., Fauci, A.S., Longo, D. L., et al.Harrison's Principles of Internal Medicine. 16th Edition. New York. McGraw-Hill. 2005.

31. Mikuls, T. R. and Saag, K. G. Comorbidity in rheumatoid arthritis. Rheum. Dis. Clin. North Am. 2001; 27: 283-303.

32. O Dell, J. R. Therapeutic strategies for RA. N. Engl. J. Med. 2004; 350: 2591-2602. 